\title{
ZmPGIP3 Gene Encodes a Polygalacturonase-Inhibiting Protein that Enhances Resistance to Sheath Blight in Rice
}

\author{
Guang Zhu, ${ }^{1}$ Enxing Liang, ${ }^{1}$ Xiang Lan, ${ }^{1}$ Qian Li, ${ }^{1}$ Jingjie Qian, ${ }^{1}$ Haixia Tao, ${ }^{1}$ Mengjiao Zhang, ${ }^{1}$ Ning Xiao, ${ }^{2}$ Shimin Zuo, ${ }^{1}$ \\ Jianmin Chen, ${ }^{1}$ and Yong Gao ${ }^{1, \dagger}$ \\ ${ }^{1}$ Jiangsu Key Laboratories of Crop Genetics and Physiology and Plant Functional Genomics of the Ministry of Education, Co-Innovation Center \\ for Modern Production Technology of Grain Crops of Jiangsu Province, Yangzhou University, Yangzhou 225009, China \\ ${ }^{2}$ Lixiahe Region Agricultural Scientific Research Institute of Jiangsu, Yangzhou 225009, Jiangsu, China \\ Accepted for publication 4 June 2019.
}

\begin{abstract}
Plant polygalacturonase-inhibiting protein (PGIP) is a structural protein that can specifically recognize and bind to fungal polygalacturonase (PG). PGIP plays an important role in plant antifungal activity. In this study, a maize PGIP gene, namely ZmPGIP3, was cloned and characterized. Agarose diffusion assay suggested that ZmPGIP3 could inhibit the activity of PG. ZmPGIP3 expression was significantly induced by wounding, Rhizoctonia solani infection, jasmonate, and salicylic acid. ZmPGIP3 might be related to disease resistance. The gene encoding ZmPGIP3 was posed under the control of the ubiquitin promoter and constitutively expressed in transgenic rice. In an $R$. solani infection assay,

wild-type rice regardless of the inoculated plant part (leaves or sheaths). Digital gene expression analysis indicated that the expression of some rice PGIP genes significantly increased in ZmPGIP3 transgenic rice, suggesting that ZmPGIP3 might activate the expression of some rice PGIP genes to resist sheath blight. Our investigation of the agronomic traits of ZmPGIP3 transgenic rice showed that ZmPGIP3 overexpression in rice did not show any detrimental phenotypic or agronomic effect. ZmPGIP3 is a promising candidate gene in the transgenic breeding for sheath blight resistance and crop improvement.
\end{abstract} ZmPGIP3 transgenic rice was more resistant to sheath blight than the
Keyword: defense-related gene
During plant growth and development, plants need to continuously absorb nutrients and energy from the environment for growth and receive abiotic and biotic stresses (De Lorenzo et al. 2001). Rice (Oryza sativa L.) is a staple food crop for the human population, and $>50 \%$ of the world's population use rice as a staple food. Similar to many other crops, rice is affected by many diseases caused by pathogenic microorganisms, leading to yield losses (Liu et al. 2014). Rice sheath blight caused by the fungus Rhizoctonia solani is the most devastating rice disease, which often results in yield loss as high as 10 to $30 \%$ (Wang et al. 2015b). Therefore, rice sheath blight resistance plays an important role in rice breeding for disease resistance.

The first barrier of plant cell protection against pathogens is the cell wall. Most fungi secrete many enzymes that degrade cell wall polymers to break through the cell wall and enter plant cells (De Lorenzo et al. 2001). Among these enzymes, polygalacturonase (PG) is secreted by pathogenic fungi to degrade the polygalacturonic acid chain, which is a major component of plant cell walls.

†Corresponding author: Y. Gao; gaoyong@yzu.edu.cn

Funding: This work was supported by National Natural Science Foundation of China grant 31771686, Natural Science Foundation of Jiangsu Province grant BK20161334, Molecular Breeding Technology Construction of Public Service Platform, Yangzhou City grant YZ2017170, Priority Academic Program Development of Jiangsu Higher Education Institutions, and State Key Laboratory of Crop Biology.

G. Zhu and E. Liang contributed equally to this work.

*The $\boldsymbol{e}$-Xtra logo stands for "electronic extra" and indicates that five supplementary figures and one supplementary table are published online.

The author(s) declare no conflict of interest.

(C) 2019 The American Phytopathological Society
To inhibit pathogens from penetrating the cell wall and infecting cells, plants have evolved various pathogen-related proteins that hinder invasion (De Lorenzo and Ferrari 2002). Polygalacturonaseinhibiting proteins (PGIPs) can specifically recognize fungal PGs and inhibit their degradative activity, thereby delaying the hydrolysis of the oligogalacturonides, cell wall fragments derived from the partial breakdown of the homogalacturonan (Cervone et al. 1989; De Lorenzo and Ferrari 2002; Federici et al. 2006). In Arabidopsis thaliana, the expression of a PG-PGIP chimera caused the apoplastic accumulation of the oligogalacturonides that, in turn, induced plant defense responses by functioning as damage-associated molecular patterns (Benedetti et al. 2015; Broetto et al. 2015; Ferrari et al. 2013).

PGIPs contain leucine-rich repeats (LRRs) and belong to the extracellular LRR protein family. The basic sequence of the LRR domain is LxxLxxLxxLxLSxNxGxIPxx. In the PGIP gene, the LRR domain is repeated 10 times and forms two $\beta$-sheets; one of them occupies the concave inner side of the molecule and contains residues crucial for the interaction with PGs (Benedetti et al. 2011, 2013; De Lorenzo and Ferrari 2002; Di Matteo et al. 2003; Feng et al. 2016; Kalunke et al. 2015). The PGIP gene has been found and characterized in $>20$ plants, including monocots and dicots. Seven PGIP genes (OsPGIP1 to OsPGIP7) are present in rice (Janni et al. 2006; Lu et al. 2012). Studies have shown that OsPGIP1 overexpression enhances resistance to sheath blight by inhibiting activity against $R$. solani $\mathrm{PG}$ in rice (Chen et al. 2016; Wang et al. 2015b). OsPGIP4 overexpression confers resistance against bacterial leaf streak in rice (Feng et al. 2016), and OsPGIP2 overexpression enhances resistance to Sclerotinia sclerotiorum in Brassica napus (Wang et al. 2018). OsPGIP5 inhibits Aspergillus niger PG in vitro (Jang et al. 2003). In the genus Arabidopsis, AtPGIP1 and AtPGIP2 proteins confer resistance to Botrytis cinerea (Ferrari et al. 2012). PGIP overexpression can reduce pathogen-induced damage by inhibiting activities to PGs in sunflower (Livaja et al. 2016), sugar beet (Li and Smigocki 2016, 
2018), mungbean (Kaewwongwal et al. 2017), grape (Agüero et al. 2005), pea (Richter et al. 2006), tobacco (Borras-Hidalgo et al. 2012; Liu et al. 2016; Wang et al. 2013), cotton (Liu et al. 2017, 2018), and wheat (Ferrari et al. 2012; Wang et al. 2015a). PGIPs from different plants play a crucial role in fungal resistance by conferring a wide spectrum of inhibitory activities to PGs.

The PGIP gene plays an important role in plant disease resistance. Its high expression level considerably limits the spread of pathogens, thereby positively affecting crop yield and quality. However, the role of PGIP in maize (Zea mays L) remains unclear. In this study, a PGIP gene known as ZmPGIP3 from maize was cloned. Its overexpression in rice enhanced the resistance to sheath blight without growth retardation. This gene could be used to improve sheath blight resistance in rice.

\section{MATERIALS AND METHODS}

Plant materials and stress treatment. Maize (hybrid line cultivar Zhengdan 958) was obtained from the Agricultural College, Yangzhou University, China. The seedlings were grown in a greenhouse under controlled conditions $\left(28^{\circ} \mathrm{C} / 26^{\circ} \mathrm{C}, 16 / 8-\mathrm{h}\right.$ photoperiod, and $70 \% \mathrm{RH})$. Stress treatments were administered in accordance with a previously reported procedure (Gao et al. 2015). For salt $(200 \mathrm{mM} \mathrm{NaCl})$, polyethylene glycol (PEG, 20\% PEG6000), cold $\left(4^{\circ} \mathrm{C}\right)$, and heat $\left(42^{\circ} \mathrm{C}\right)$ stress, leaves of $\geq 10$ seedlings were sampled at $0,1,3,24$, and $48 \mathrm{~h}$. For wound treatment, the fourth leaf was chopped into $1 \mathrm{~mm}$-long pieces with a knife and incubated on moist filter paper at $28^{\circ} \mathrm{C}$. For $R$. solani infection, each matchstick with a mycelial ball was fixed on the sheath of a 6 -week-old plant, and stems of $\geq 10$ seedlings were sampled at 0,24, 48, and $72 \mathrm{~h}$. For abscisic acid (ABA), gibberellin (GA), brassinosteroid (BR), jasmonate (JA), salicylic acid (SA), auxin (IAA), and ethylene (ETH) treatments, a nutrient solution was supplied with $100 \mu \mathrm{M}$ ABA, $100 \mu \mathrm{M}$ gibberellin A3 (GA3), $100 \mu \mathrm{M}$ BR, $100 \mu \mathrm{M}$ methyl jasmonate (M-JA), $100 \mu \mathrm{M}$ SA, $100 \mu \mathrm{M}$ IAA, or $100 \mu \mathrm{M} \mathrm{ETH}$, respectively. Leaves of $\geq 10$ seedlings were sampled at $0,1,3,24$, and $48 \mathrm{~h}$ after treatment. Three separate biological replicates were prepared for the quantitative reverse transcription PCR (qRT-PCR) experiments.

Transgenic rice was prepared in accordance with a previously reported procedure (Gao et al. 2015). Rice (cultivar Wuyunjing) was grown in a greenhouse under controlled conditions $\left(28^{\circ} \mathrm{C} /\right.$ $25^{\circ} \mathrm{C}, 16 / 8$-h photoperiod, and $70 \% \mathrm{RH}$ ).

Cloning of the full-length complementary DNA and sequence analysis of ZmPGIP3. A novel complementary DNA (cDNA) sequence, named as the ZmPGIP3 gene, was obtained from GenBank and MaizeGDB (https://www.ncbi.nlm.nih.gov/ and https://www.maizegdb.org/, respectively) on the basis of previous DGE sequencing results (Gao et al. 2016). The obtained sequences of ZmPGIP3 were analyzed using bioinformatic tools at https:// www.ncbi.nlm.nih.gov/, http://planttfdb.cbi.pku.edu.cn/, and https:// www.expasy.org/. A phylogenetic tree was constructed using MEGA version 6 (Tamura et al. 2013).

Subcellular localization of the ZmPGIP3 protein. Subcellular localization analysis was performed in accordance with previously described methods (Brandizzi et al. 2002; Gao et al. 2018). The full open reading frame of ZmPGIP3 was cloned into a green fluorescent protein (GFP) expression vector to investigate the subcellular localization of ZmPGIP3 in tobacco leaves. The expression vector was introduced to Agrobacterium tumefaciens strain EHA105. A single colony of transformants was incubated to transform the tobacco. The bacterial specimens, tobacco seedlings, and tobacco inoculation were prepared. The fluorescence emitted by the fusion proteins was observed for 36 to $72 \mathrm{~h}$ after inoculation under a fluorescent or confocal microscope.

Expression of the ZmPIGP3 protein in vitro. The product was subcloned into the protein expression vector pCold I (TaKaRa, code no. 3361), and the His-tagged fusion protein expression construct ZmPGIP3-pCold I was generated. The ZmPIGP3 protein was expressed in vitro in accordance with a previously reported procedure (Chen et al. 2016). ZmPGIP3-pCold I was introduced to Escherichia coli BL21 to express the fusion protein on induction with isopropyl $\beta$-D-thiogalactoside (IPTG). The bacterial cells were collected and disrupted in an ultrasonic bath. A His-tagged fusion protein (His-ZmPGIP3) was partially purified using Hisbind resin (Novagen) in accordance with the manufacturer's protocol.

Agarose diffusion assay. Agarose diffusion assay was performed in accordance with a previously reported procedure (Chen et al. 2016). In this assay, plate determination was conducted with a reaction mixture containing $0.8 \%$ agarose and $0.5 \%$ pectin oligogalacturonic acid (PGA) with $50 \mathrm{mM} \mathrm{NaAC}$ buffer (pH 4.7). PGs were purified from $R$. solani (Chen et al. 2016). Five small holes with a diameter of $0.5 \mathrm{~cm}$ were drawn on the plate. Then, $20 \mu \mathrm{l}$ of PGs, $20 \mu \mathrm{l}$ of PGs $+10 \mu \mathrm{l}$ of ZmPGIP3, $20 \mu \mathrm{l}$ of PGs $+10 \mu \mathrm{l}$ of boiled ZmPGIP3, $20 \mu \mathrm{l}$ of ZmPGIP3, and $20 \mu \mathrm{l}$ of phosphate buffer were added to each well. After PG or ZmPGIP3 was added, the mixture was incubated at $30^{\circ} \mathrm{C}$ for $12 \mathrm{~h}$ (Wang et al. 2013). The PG activity was expressed as agarose diffusion diameter after $1 \mathrm{~min}$ of treatment with $6 \mathrm{M} \mathrm{HCl}$. Each experiment was repeated three times.

Quantitative real-time PCR. Reverse transcription PCR (RT-PCR) and qRT-PCR analyses were performed in accordance with a previously reported procedure (Gao et al. 2018). Quantitative PCR primers were designed and synthesized on the basis of the sequences of ZmPGIP3 (Supplementary Table S1). Reverse transcription reactions were performed using total RNA from maize or rice tissues. First-strand cDNA was synthesized from DNase-treated total RNA with Transcriptor Reverse transcription (Roche) and oligo(dT)18 in accordance with the manufacturer's instructions. Real-time PCR was performed using an ABI 7300 system with an SYBR Green Master Mix kit (Roche). Three replicate reactions were routinely performed for each sample.

Transformation of ZmPGIP3 in rice. ZmPGIP3 was transformed in accordance with a previously reported procedure (Gao et al. 2018). The full open reading frame of ZmPGIP3 was cloned into p1011 vector and transformed into rice embryonic calli by A. tumefaciens-meditated methods (Gao et al. 2015, 2018). ZmPGIP3 transgenic rice plants were selected in a 1/2 Murashige \& Skoog (MS) medium containing $50 \mathrm{mg} /$ liter hygromycin. Phenotypic analyses were performed using T3 homozygous lines.

Bioassay. $R$. solani mycelia or sclerotia were placed onto potato dextrose agar and grown at $30^{\circ} \mathrm{C}$. The strain used for inoculation was provided by the Agriculture College of Yangzhou University. Bioassay using isolated leaves was performed in accordance with a previously reported procedure (Molla et al. 2013). A sterilization box was lined with a sterile cotton pad containing sterile distilled water. A 10-cm piece of fresh young leaf was sterilized and placed in a box. A 1-cm-diameter mycelium disk was placed in the middle of the leaf surface. The percentage of the infected area in the total leaf area was measured using Image ProPlus6.0 with the following equation: percentage of infected area $=$ lesion area/leaf area $=$ lesion area pixel/leaf area pixel. The tests were repeated at least four times.

Sheath blight inoculation was performed and improved using a matchstick embedding method instead of the toothpick embedding method (Chen et al. 2016). Matchsticks were used to inoculate $R$. solani. The inoculation position was the third sheath at the top of the rice. Each matchstick with a mycelial ball was fixed on the sheath of a 6-week-old plant and removed when disease symptoms began to appear 2 days after inoculation. The percentage of the infected length in the total stem length was measured using Image ProPlus6.0 with the following equation: relative lesion length $(\%)=$ total lesion length/total stem length = pixel length of the lesion area/ pixel length of stem. The tests were repeated at least three times.

Digital gene expression profiling (DGE) analysis. Two sets of total RNA were prepared. One set was derived from the 
original RNA pool prepared from wild-type (WT) and ZmPGIP3 transgenic rice seedlings without the infection. The other set was obtained from the RNA pool derived from WT and ZmPGIP3 transgenic rice seedlings 2 days after $R$. solani infection. DGE analysis was performed in accordance with a previously reported procedure (Gao et al. 2018). Ten wellgrown seedlings of WT plants and ZmPGIP3 transgenic rice seedlings were selected. The third sheath of WT and ZmPGIP3 transgenic seedlings was rapidly cut, frozen, and stored. Under normal conditions, three repetitions of WT control were set and named WT1_0, WT2_0, and WT3_0. Three transgenic lines, namely OE1, OE2, and OE3, were also set as three replicates of ZmPGIP3 transgenic rice and named OE1_0, OE2_0, and OE3_ 0 , respectively. Three repetitions of WT control were set 2 days after inoculation with $R$. solani and named WT1_2, WT2_2, and WT3_2. Three transgenic lines OE1, OE2, and OE3 were set as three replicates of ZmPGIP3 transgenic rice and named OE1_2, OE2_2, and OE3_2, respectively. Total RNA was extracted in accordance with the instructions provided in the RNAprep Pure Plant Kit. DGE was performed in accordance
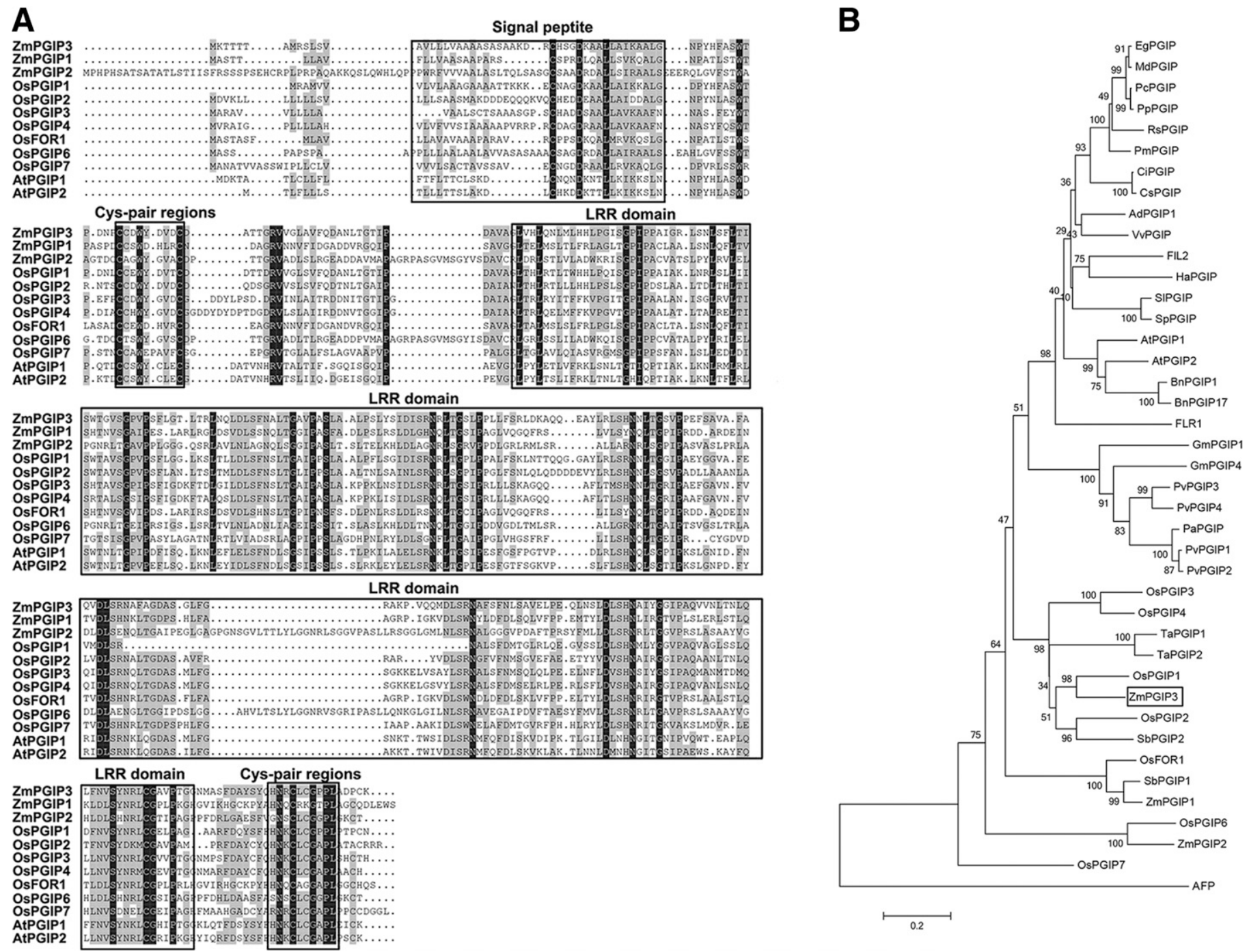

Fig. 1. Sequence alignment and phylogenetic tree analysis of ZmPGIP3 with other polygalacturonase-inhibiting protein (PGIP) family members. A, Sequence alignment of ZmPGIP3 with other PGIP proteins. The comparison of the putative amino acid sequence of ZmPGIP3 with the other plant PGIP proteins. Identical amino acids are shown in black with a white background, and the conserved amino acids are shown in white with black background. The specific sites of the signal peptide, Cys-pair regions, and leucine-rich repeat (LRR) domain are presented. The aligned PGIP sequences are from maize, rice, and the genus Arabidopsis. Sequences used in this analysis were as follows: Zea mays ZmPGIP1 (GenBank accession no. NP_001147517) and ZmPGIP2 (GenBank accession no. NP_ 001150670); Oryza sativa OsPGIP1 (GenBank accession no. CAJ55691), OsPGIP2 (GenBank accession no. CAJ55692), OsPGIP3 (GenBank accession no. CAJ55693), OsPGIP4 (GenBank accession no. CAJ55694), OsFOR1 (GenBank accession no. AAO17320), OsPGIP6 (GenBank accession no. NP_001062185), and OsPGIP7 (GenBank accession no. EEE69955); and Arabidopsis thaliana AtPGIP1 (GenBank accession no. AAF69827) and AtPGIP2 (GenBank accession no. AAF69828). B, Phylogenetic tree analysis of ZmPGIP3 with other PGIP family members. The neighbor-joining method was used to construct the tree. The amino acid sequences used in phylogenetic tree analysis were obtained from plants. They included Pyrus pyrifolia PpPGIP (GenBank accession no. ACY56891); Pyrus communis PcPGIP (GenBank accession no. AAA33865); Malus $\times$ domestica MdPGIP (GenBank accession no. AAB19212); Eucalyptus grandis EgPGIP (GenBank accession no. AAF22248); Prunus mahaleb PmPGIP (GenBank accession no. AAF79181); Rhodotypos scandens RsPGIP (GenBank accession no. AAK43455); Citrus sinensis CsPGIP (GenBank accession no. CAA69910); Citrus ivo CiPGIP (GenBank accession no. BAA31843); Vitis vinifera VvPGIP (GenBank accession no. AAM74142); Actinidia deliciosa AdPGIP (GenBank accession no. CAA88846); Solanum palustre SpPGIP (GenBank accession no. AAT77428); Solanum lycopersicum SIPGIP (GenBank accession no. AAA53547); Brassica napus BnPGIP1 (GenBank accession no. ABX46548) and BnPGIP17 (GenBank accession no. ABX46563); A. thaliana AtPGIP1 and AtPGIP2; Helianthus annuus HaPGIP (GenBank accession no. ABW89508); Antirrhinum majus FIL2 (GenBank accession no. CAA54303) and FIL2 (GenBank accession no. CAA54303); Triticum aestivum TaPGIP1 (GenBank accession no. CAJ55695) and TaPGIP2 (GenBank accession no. CAJ55696); O. sativa OsPGIP1, OsPGIP2, OsPGIP3, OsPGIP4, OsFOR1, OsPGIP6, and OsPGIP7; Sorghum bicolor SbPGIP1 (GenBank accession no. XP_002463048) and SbPGIP2 (GenBank accession no. XP_002439097); Glycine max GmPGIP1 (GenBank accession no. CAI99392) and GmPGIP4 (GenBank accession no. CAI99395); Phaseolus vulgaris PvPGIP1 (GenBank accession no. CAH10215), PvPGIP2 (GenBank accession no.CAH10216), PvPGIP3 (GenBank accession no. CAH10217), and PvPGIP4 (GenBank accession no. CAH10218); and Z. mays ZmPGIP1 and ZmPGIP2. 
with the standard protocol of Beijing Genomics Institute (http://www.genomics.cn/index).

Grain yield analysis. The homozygous (T5) lines of ZmPGIP3 and WT plants were planted in Jiangsu Province, China to evaluate the yield of transgenic plants under normal field conditions. At the time of harvest, agronomic traits of 15 to 30 plants per transgenic line and WT rice were statistically analyzed.

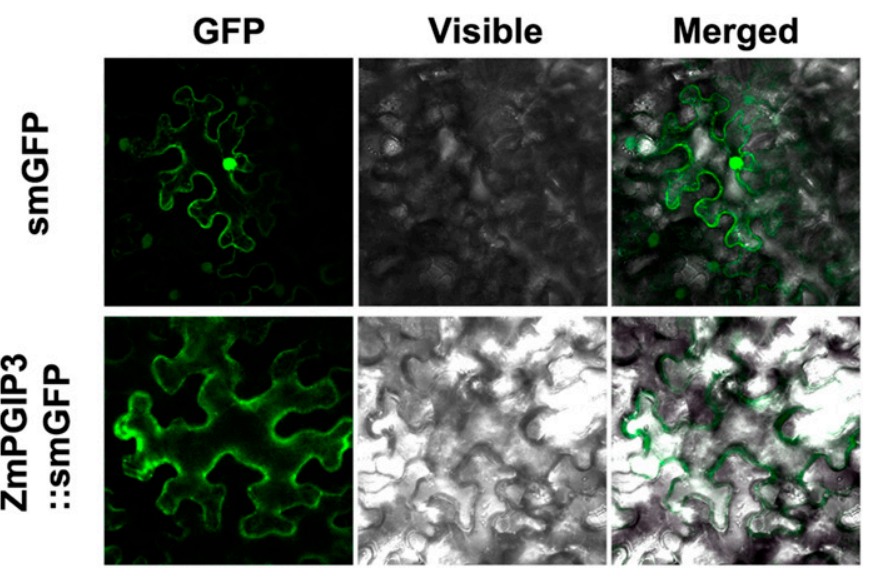

Fig. 2. Subcellular localization of ZmPGIP3. Full-length ZmPGIP3 fused to green fluorescent protein (GFP) was transiently transformed into tobacco cells. Images were taken using a confocal microscope (GFP fluorescence, green; visible, visible light image; merged, merged images of the three aforementioned images). Cells transformed with an empty vector (smGFP) are shown as a control.
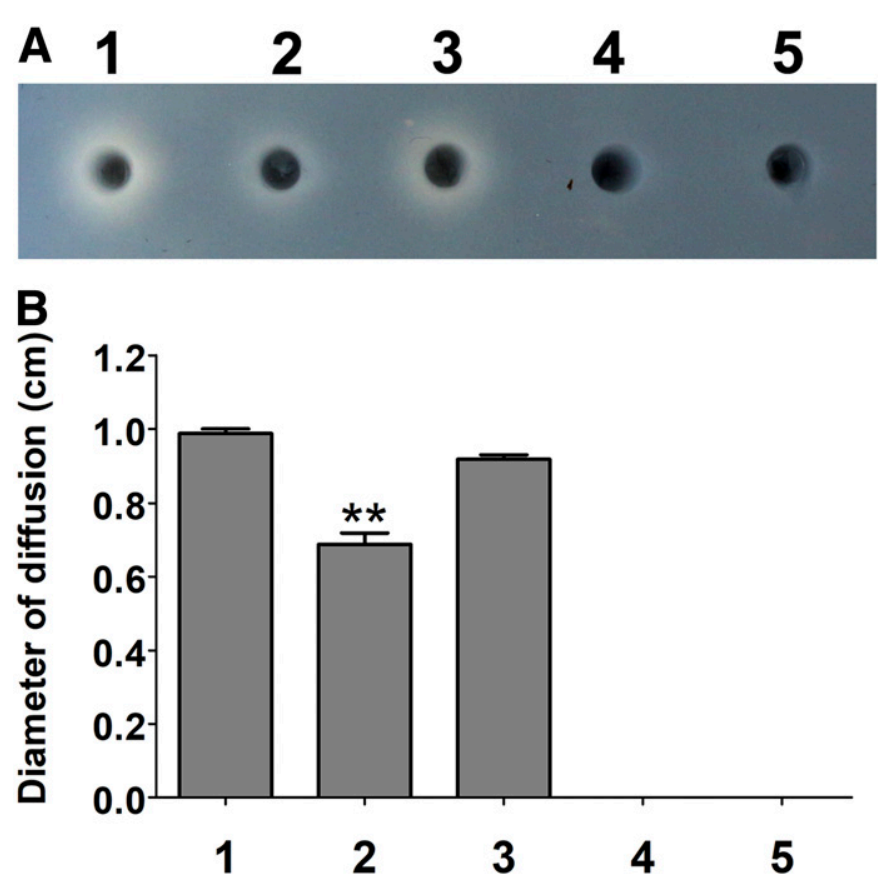

Fig. 3. Inhibitory activity of ZmPGIP3 against polygalacturonases (PGs) from Rhizoctonia solani. A, Evaluation of PG activity as determined by agar diffusion assay. (1) PGs from $R$. solani, (2) mixture of PGs and ZmPGIP3 protein, (3) mixture of PGs and boiling ZmPGIP3 protein, (4) ZmPGIP3 protein, and (5) phosphate buffer. The diameter of the halo is proportional to the PG activity. B, Measurement of the halos from the same agar diffusion assay shown in $\mathbf{A}$ expressed as diameter of diffusion. Statistical significance was calculated according to the Student $t$ test. The ordinate is the diameter of diffusion, and the abscissa is the different infection patterns $(n>4)$. Data represent the mean \pm standard error. $* * t$ test with $P<0.01$.

\section{RESULTS}

Molecular characterization of ZmPGIP3. ZmPGIP3 was screened from maize by transcriptome sequencing. The full-length cDNA sequence of ZmPGIP3 contained an open reading frame of $1,023 \mathrm{bp}$. BLAST indicated that the amino acid sequence of ZmPGIP3 was highly similar to those of $O$. sativa PGIPs OsPGIP1 $(61.71 \%)$, OsPGIP2 $(58.91 \%)$, OsPGIP3 $(57.18 \%)$, OsPGIP4 (56.66\%), OsPGIP5 (42.27\%), OsPGIP6 (31.23\%), and OsPGIP7 $(40.00 \%)$ and maize PGIPs ZmPGIP1 $(42.24 \%)$ and ZmPGIP2 $(27.93 \%)$. Three characteristic domains, namely the LRR domain, the Cys-pair regions, and the specific sites of the signal peptide, were found in the ZmPGIP3 amino acid sequence (Fig. 1A). The comparison of the ZmPGIP3 amino acid sequence with other plant PGIP family proteins via molecular phylogenetic tree analysis revealed that ZmPGIP3 was closely related to OsPGIP1 and OsPGIP2 in rice and SbPGIP2 in Sorghum bicolor (Fig. 1B).

A fusion protein with GFP was expressed and localized using a laser scanning confocal microscope to identify the cellular localization of ZmPGIP3. ZmPGIP3-GFP was present in the cell membrane or cell wall. Therefore, ZmPGIP3 was likely localized to the cell membrane or cell wall (Fig. 2).

In vitro inhibition profile of ZmPGIP3. ZmPGIP3-pCold I expression vector was constructed and transformed into $E$. coli BL21 by using pCold I as a prokaryotic expression vector. The expression of ZmPGIP3 was induced by IPTG. The ZmPGIP3 protein could be detected in the supernatant (Supplementary Fig. S1). The ZmPGIP3 was partially purified by passing the protein extract through a His resin, and its ability to inhibit a mixture of PGs from $R$. solani was evaluated by activity assay. The results revealed that ZmPGIP3 inhibited PGs. The diffusion circles around ZmPGIP3 pores were significantly smaller than those of the two
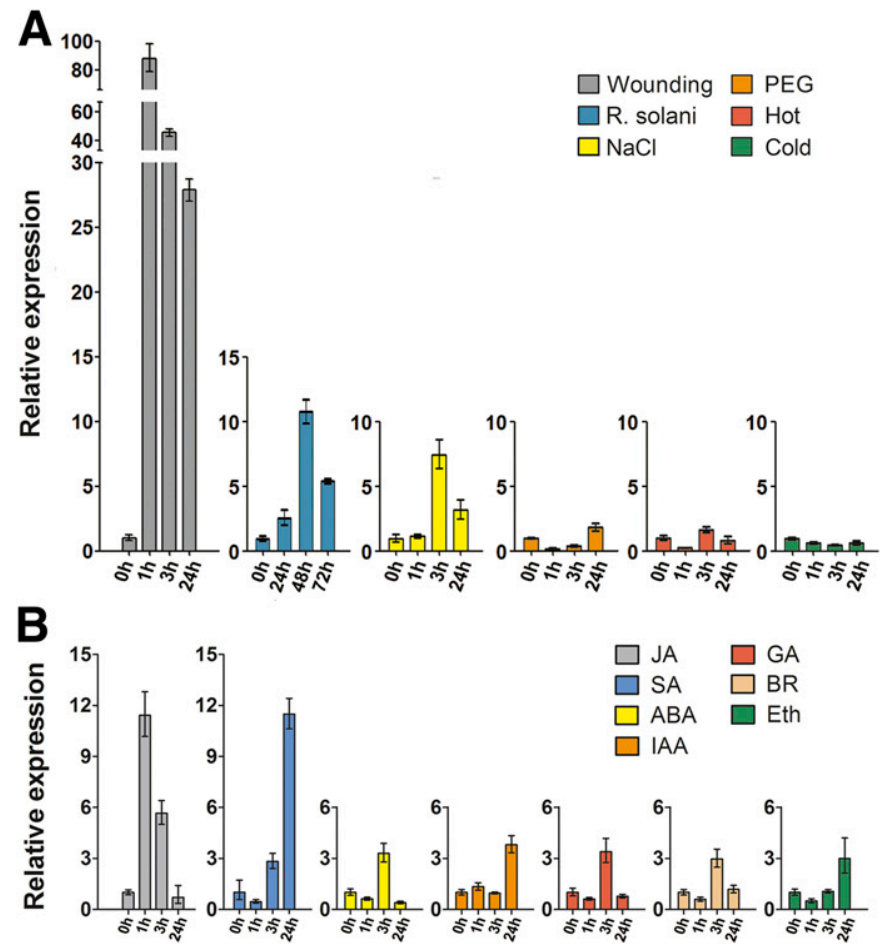

Fig. 4. Expression patterns of ZmPGIP3 under various stresses and hormones in seedlings. A, Expression patterns of ZmPGIP3 under various stress treatments $(n>15)$ : wounding stress, Rhizoctonia solani infection, drought stress (20\% polyethylene glycol 6000, 20\% PEG6000), salt stress (250 mM NaCl), high-temperature stress $\left(42^{\circ} \mathrm{C}\right)$, and low-temperature stress $\left(4^{\circ} \mathrm{C}\right)$. B, Expression patterns of ZmPGIP3 under various hormone treatments $(n>15)$. The concentration of each hormone treatment was $100 \mu \mathrm{M}$. ABA, abscisic acid; BR, brassinosteroid; GA, gibberellin; SA, salicylic acid; IAA, auxin; Eth, ethylene; JA, jasmonate. 
other controls (Fig. 3A). The statistical results also confirmed that the diffusion ring diameter of ZmPGIP3 plus PG was significantly shorter than that of PG and that of boiled ZmPGIP3 plus PGs from $R$. solani, confirming the protein nature of such inhibition (Fig. 4B).

Expression patterns of ZmPGIP3 under stress and hormone. The expression levels of ZmPGIP3 significantly varied in various tissues and were the highest in the roots (Supplementary Fig. S2). The expression levels of ZmPGIP3 under wounding, $R$. solani infection, salt, PEG, and high- and low-temperature treatments were examined. The expression levels of ZmPGIP3 under wounding treatment significantly increased after $1 \mathrm{~h}$, and the response was the strongest under wounding: that is, the peak was 88.08-fold higher than that of the control. The expression levels at $24 \mathrm{~h}$ were still higher than those at $0 \mathrm{~h}$ (27.89-fold) under wounding treatment (Fig. 4A). The expression levels of ZmPGIP3 after $48 \mathrm{~h}$ of inoculation with $R$. solani were significantly increased (peaking at 10.83-fold of the control). The expression levels of ZmPGIP3 were still higher than those at $0 \mathrm{~h}(5.48$-fold $)$ after $72 \mathrm{~h}$ of inoculation with $R$. solani (Fig. 4A). The expression level of ZmPGIP3 was significantly higher after $3 \mathrm{~h}$ of exposure to $250 \mathrm{mM} \mathrm{NaCl}$ than that of the control (Fig. 4A). For other treatments, the expression of ZmPGIP3 was not significantly induced.

The expression patterns of ZmPGIP3 in response to exogenous JA, SA, ABA, IAA, GA, BR, and ETH are shown in Figure 4B. The expression patterns were compared with those of the control (hormone concentration was zero). The expression levels of ZmPGIP3 significantly increased under JA and SA treatments. Under JA treatment, the expression levels of ZmPGIP3 peaked at $1 \mathrm{~h}$ and reached 11.41-fold. The highest expression levels of ZmPGIP3 were obtained (11.48-fold) $24 \mathrm{~h}$ after the SA treatment. By contrast, the expression of ZmPGIP3 was not significantly induced by the other hormones (Fig. 4B).

Enhancement of the resistance to sheath blight in rice via ZmPGIP3 overexpression. An overexpression construct was transformed into Wuyunjing rice to study the function of ZmPGIP3. Seven transgenic lines were confirmed via hygromycin selection, RT-PCR, and qRT-PCR (Supplementary Fig. S3). Three of the lines (OE-1, OE-2, and OE-3) were used to test disease resistance. Under normal growth conditions, no phenotypic differences were observed between homozygous T3 transgenic lines and the WT (data not shown).

The leaves were selected from the same parts of transgenic and WT rice and infected with $R$. solani to study the role of ZmPGIP3 in disease resistance. In comparison with the leaves of the WT rice, the leaves of the ZmPGIP3 transgenic lines showed small and discontinuous lesions and short lesion spreading (Fig. 5A). Statistical results showed that the WT rice was more susceptible to infection, and the infected area of the WT rice was considerably larger than that of the transgenic rice as the duration of infection increased (Fig. 5B). In the plant bioassay, the sheaths of 6-week-old transgenic and WT rice were infected with $R$. solani. The plants, especially WT plants, were infected by the pathogen 2 days after inoculation with $R$. solani. A large area was infected 5 days after inoculation with $R$. solani, and the relative lesion length reached $50 \%$ in WT plants. The relative lesion length of the WT plants was considerably higher than those of the three transgenic lines
A wT

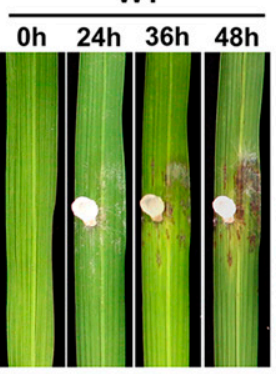

OE1

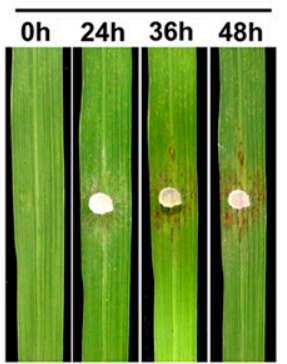

OE2

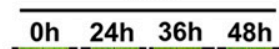

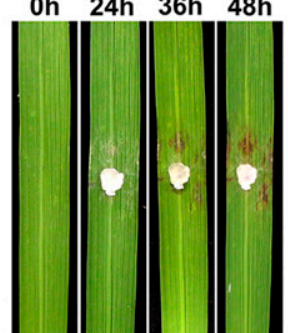

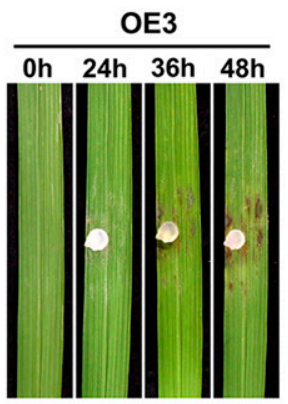

B

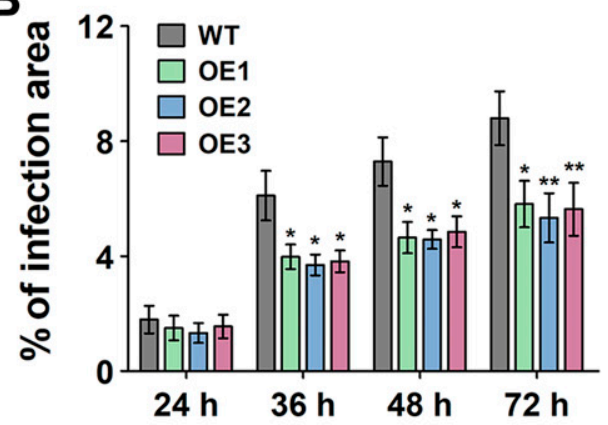

C

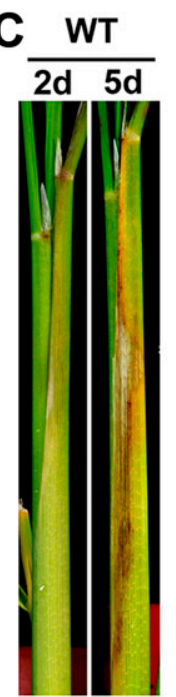

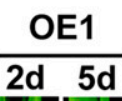

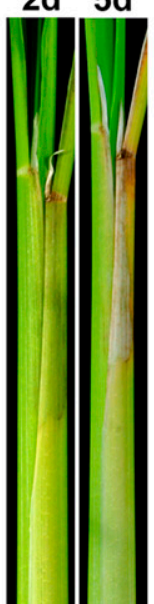

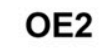

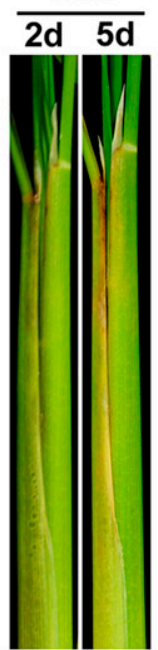

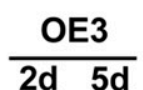

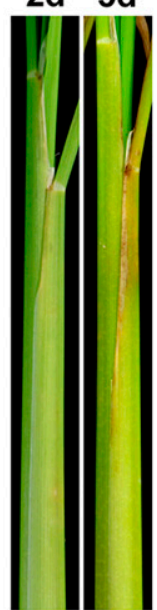

D

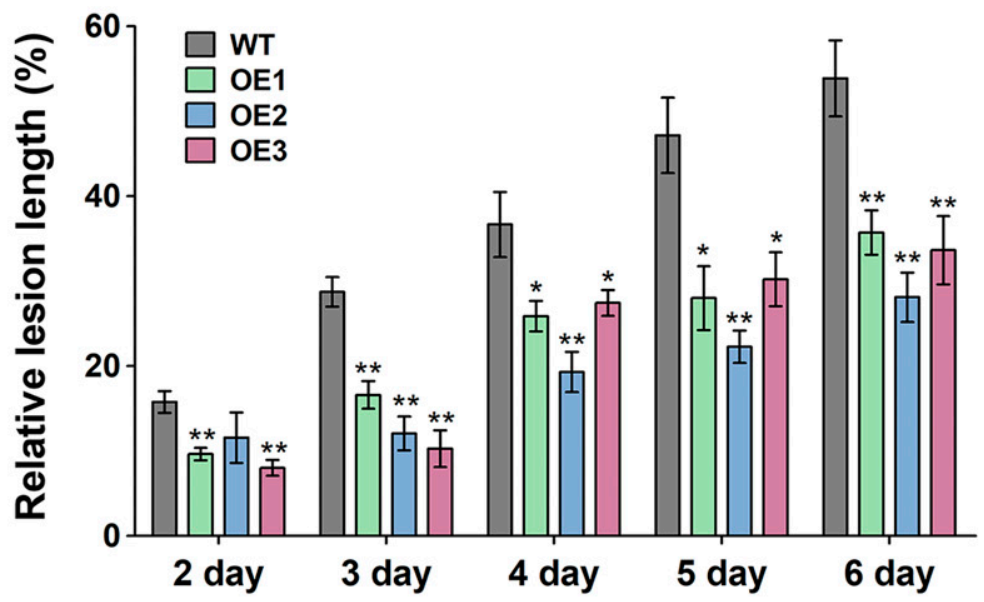

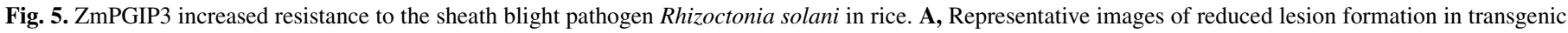

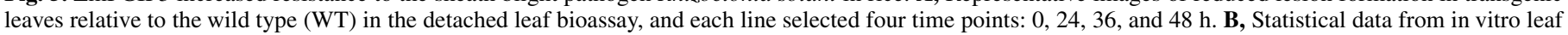

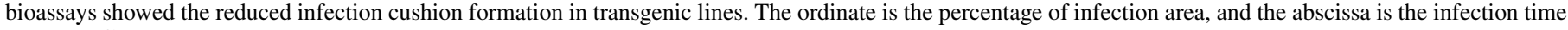

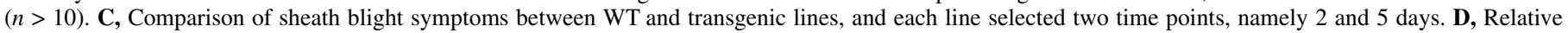

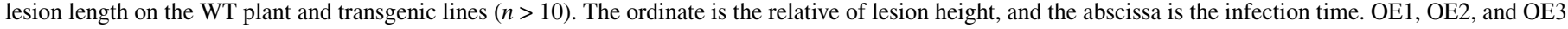
are three ZmPGIP3 transgenic lines. Data represent the mean \pm standard error. $* t$ test with $P<0.05$; **t test with $P<0.01$. 
(Fig. 5C). Statistical results also revealed that the infection degree of the transgenic plants was less than that of the WT plants after inoculation with $R$. solani (Fig. 5D).

Effects of ZmPGIP3 on differential gene expression in rice. The samples of $\mathrm{WT}$ and $\mathrm{ZmPGIP} 3$ transgenic rice under normal conditions and 2 days after inoculation with $R$. solani were used to construct RNA-seq libraries. Three repeats of WT1_0, WT2_0, and WT3_0 normalized to WT-0d; OE1_0, OE2_0, and OE3_0 normalized to OE-0d; WT1_2, WT2_2, and WT3_2 normalized to WT-2d; and OE1_2, OE2_2, and OE3_2 normalized to $\mathrm{OE}-2 \mathrm{~d}$ were prepared to reveal the underlying molecular mechanisms (Table 1). Under normal growth conditions, 1,886 genes were upregulated and 670 genes were downregulated in the ZmPGIP3 transgenic rice compared with those in the WT rice. A total of 1,987 genes were upregulated and 1,154 genes were downregulated in the ZmPGIP3 transgenic rice compared with those in the WT rice 2 days postinoculation.
In comparison with the WT rice, the $\mathrm{ZmPGIP} 3$ transgenic rice revealed significant differences in the expression of PGIP-related, resistance-related, and plant hormone signal-related genes (Table 1 and Supplementary Figs. S4 and S5, respectively). The expression levels of some rice PGIP family genes, including OsPGIP1 (LOC_ Os05g01380), OsPGIP2 (LOC_Os05g01370), and OsPGIP4 (LOC_Os05g01444), significantly increased in the ZmPGIP3 transgenic rice compared with that in the WT rice (Table 1). OsPGIP1 had the highest homology with ZmPGIP3 (Fig. 1B). Under normal growth conditions, the expression level of OsPGIP1 was significantly higher (7.5-fold) in the ZmPGIP3 transgenic rice than in the WT rice. The expression level of OsPGIP1 increased to 7.8 -fold in the WT rice compared with that in the WT rice under normal growth conditions 2 days postinoculation. The expression levels of OsPGIP2 and OsPGIP4 were consistent with that of OsPGIP1. Under normal growth conditions, the expression levels of OsPGIP2 and OsPGIP4 in the transgenic rice were significantly

TABLE 1. Expression of polygalacturonase-inhibiting protein (PGIP)-related genes, resistance-related genes, and plant hormone signal transduction identified by digital gene expression profiling (DGE) tag profiling ${ }^{\mathrm{a}}$

\begin{tabular}{|c|c|c|c|c|c|}
\hline \multirow[b]{3}{*}{ Gene identification } & \multirow[b]{3}{*}{ Description } & \multicolumn{4}{|c|}{$\log _{2}$ ratio } \\
\hline & & OE-Od & WT-2d & OE-2d & OE-2d \\
\hline & & WT-0d & WT-0d & WT-2d & OE-Od \\
\hline LOC_Os05g01380 & $\begin{array}{l}\text { Polygalacturonase-inhibiting protein } 1 \\
\text { (OsPGIP1) }\end{array}$ & 7.5593 & 7.8203 & 0.0754 & 0.3364 \\
\hline LOC_Os05g01370 & $\begin{array}{l}\text { Polygalacturonase-inhibiting protein } 2 \\
\text { (OsPGIP2) }\end{array}$ & 6.4489 & 5.5005 & 1.3972 & 0.4488 \\
\hline \multicolumn{6}{|l|}{ Resistance-related genes } \\
\hline LOC_Os06g51050 & Chitinase (OsCHI11) & 3.1442 & 6.8753 & -2.4719 & 1.2592 \\
\hline LOC_Os01g71080 & $\begin{array}{l}\text { Chitinase-like protein, xylanase inhibitor } \\
\text { (OsCLP) }\end{array}$ & 2.5909 & 2.9875 & -0.6545 & -0.258 \\
\hline LOC_Os04g52780 & $\begin{array}{l}\text { Leucine-rich repeat receptor-like serine/ } \\
\text { threonine-protein kinase FLS2 (OsFLS2) }\end{array}$ & 2.3926 & 2.2874 & -0.1743 & -0.2794 \\
\hline LOC_Os08g08960 & $\begin{array}{l}\text { Leucine-rich repeat protein kinase family } \\
\text { protein (OsGLP8-2; GER3) }\end{array}$ & 6.7873 & 5.4469 & 0.0877 & -1.2528 \\
\hline LOC_Os01g16400 & $\begin{array}{l}\text { Leucine-rich repeat protein, putative disease } \\
\text { resistance RPP13-like protein } 3\end{array}$ & 1.5780 & 1.2475 & 0.0579 & -0.2725 \\
\hline LOC_Os11g30060 & $\begin{array}{l}\text { Leucine-rich repeat protein, putative disease } \\
\text { resistance RPP13-like protein } 1\end{array}$ & 2.0566 & 1.9350 & -0.8244 & -0.946 \\
\hline LOC_Os05g45230 & WRKY transcription factor (OsWRKY58) & 1.5549 & 1.7694 & 0.1592 & 0.3737 \\
\hline LOC_Os10g42850 & WRKY transcription factor (OsWRKY2) & 3.6635 & 5.2372 & -4.2262 & -2.6525 \\
\hline LOC_Os08g01330 & NAC transcription factor (OsSWN3) & 2.7697 & 2.2098 & 0.2386 & -0.3213 \\
\hline LOC_Os11g03300 & NAC transcription factor (OsNAC10) & 1.7791 & 0.7628 & 0.2029 & -0.8134 \\
\hline LOC_Os05g24780 & Calmodulin (OsCML21) & 2.9602 & 7.3003 & -0.9230 & 3.4172 \\
\hline LOC_Os12g35610 & $\begin{array}{l}\text { Rice respiratory burst oxidase homolog } \\
\text { (Osrboh9) }\end{array}$ & 2.4442 & 3.6105 & -1.9114 & -0.7451 \\
\hline LOC_Os01g14550 & Pathogen-related protein & 3.5441 & 2.3731 & -0.9008 & -2.0718 \\
\hline LOC_Os01g53100 & Ubiquitin family protein & 4.6863 & 8.3544 & -2.0443 & 1.6237 \\
\hline LOC_Os09g25070 & WRKY transcription factor (OsWRKY62) & 1.8793 & 3.0315 & 0.5070 & 1.6592 \\
\hline LOC_Os10g39260 & Aspartic protease 77 (OsAP77) & 3.3594 & 2.9927 & -0.3482 & -0.7149 \\
\hline LOC_Os12g26290 & Alpha-DOX2 & 2.2133 & 5.2082 & -0.9104 & 2.0845 \\
\hline LOC_Os04g12970 & $\begin{array}{l}\text { Pathogen-inducible salicylic acid } \\
\text { glucosyltransferase }\end{array}$ & 6.2566 & 8.3963 & -1.1053 & 1.0345 \\
\hline LOC_Os01g57770 & Salicylic acid-binding protein (OsPOP4) & 1.5339 & 3.7137 & -2.3281 & -0.1483 \\
\hline
\end{tabular}

${ }^{a}$ Genes with at least a 1.5-fold change in the ZmPGIP3 transgenic rice are shown. OE-0d, ZmPGIP3 transgenic lines without infection; OE-2d, ZmPGIP3 transgenic lines inoculated with Rhizoctonia solani for 2 days; WT-0d, wild-type plant without infection; WT-2d, wild-type plant inoculated with $R$. solani for 2 days. 
higher (6.4- and 6.3-fold) than those in the WT rice. The expression levels of OsPGIP2 and OsPGIP4 were also significantly increased in the WT rice compared with those in the WT rice under normal growth conditions 2 days postinoculation.

OsCHIII and OsCLP exhibit chitinase activity. In this study, the expression levels of OsCHI11 and OsCLP increased in the ZmPGIP3 transgenic rice compared with those in the WT rice. The expression of some LRR family genes, such as OsFLS2, OsGLP8-2, LOC_Os11g07100, LOC_Os01g64310, LOC_Os01g16400, and LOC107279373, increased in the ZmPGIP3 transgenic rice compared with that in the WT rice. In addition, the expression of some other disease-resistant genes, such as WRKY and NAC transcription factor, increased in the transgenic rice compared with that in the WT rice (Table 1)

JA and SA are closely related to disease resistance in plants. In this study, the expression level of OsLOX2 (LOC_Os03g52860), a JA-related pathway gene, was significantly increased in ZmPGIP3 transgenic rice. The expression levels of some SA-related pathway genes, including OsWRKY62 (LOC_Os09g25070), OsAP77 (LOC_Os10g39260), ALDOX1 (LOC_Os12g26290), and pathogen-

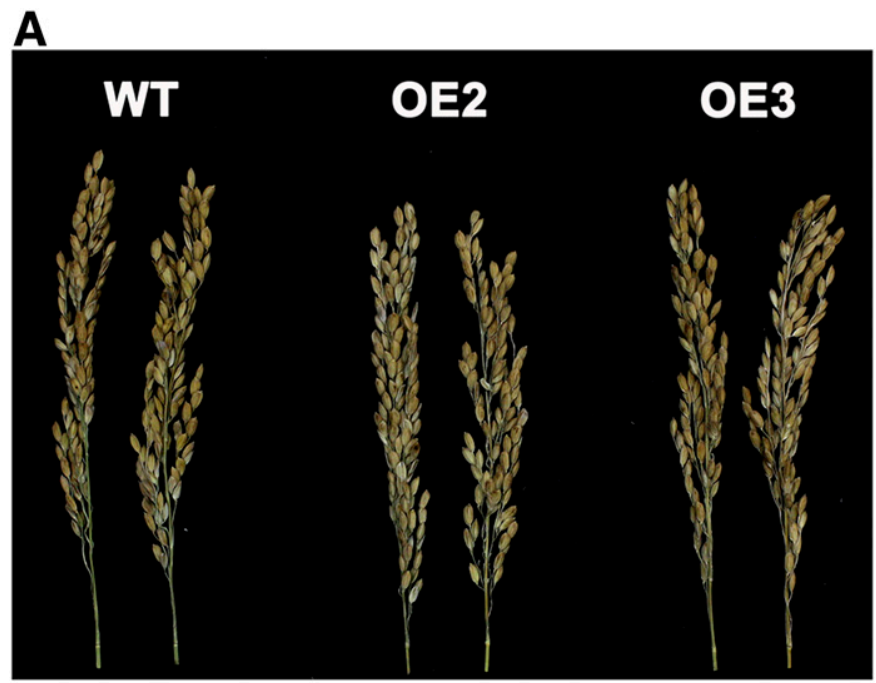

B

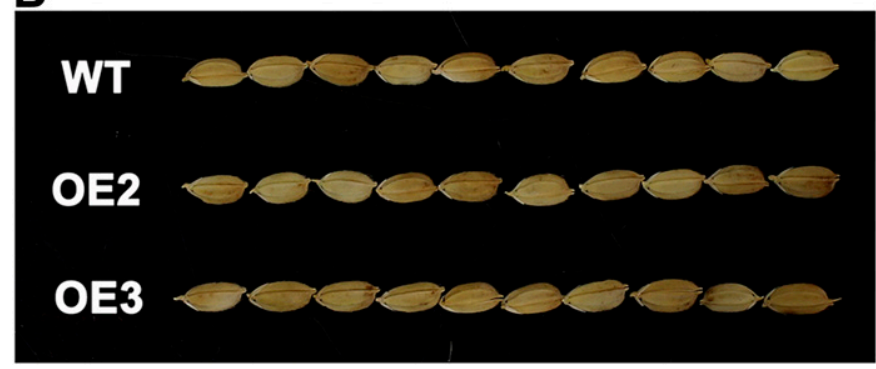

Fig. 6. A, Panicle phenotype and $\mathbf{B}$, seed morphology of ZmPGIP3 transgenic and wild-type (WT) rice. Agronomic traits of the ZmPGIP3 transgenic rice under normal conditions in 2018. OE1, OE2, and OE3 are three ZmPGIP3 transgenic lines. inducible salicylic acid glucosyltransferase (LOC_Os04g12970), were upregulated by at least 1.5 -fold (Table 1 ).

Grain yield of the ZmPGIP3 transgenic rice. Several agronomic traits of the ZmPGIP3 transgenic rice were examined under normal conditions. The transgenic lines OE2 and OE3 (homozygous T5) were chosen for the field trials. No significant changes were observed in the various tests compared with those in transgenic rice and the WT (Fig. 6 and Table 2, respectively). The 1,000-grain weight of the transgenic rice markedly increased, and the increase seemed to be balanced by the reduction in the number of filled grains per panicle (Table 2). These results demonstrated that ZmPGIP3 did not affect grain yield.

\section{DISCUSSION}

During the fungal infection, plant immune PGIPs which as structural components of the plant cell wall are induced, thereby inhibiting PG function and preventing cell wall degradation from limiting fungal growth (Di Matteo et al. 2006; Federici et al. 2006; Juge 2006). PGIP genes have been identified in different plants. In this study, ZmPGIP3, a PGIP gene in maize, was identified. ZmPGIP1 and ZmPGIP2 have been found in maize through genome analysis, but their functions have yet to be reported. Similar to other PGIP genes, ZmPGIP3 had conserved LRR domains, signal peptide regions, and cysteine residues (Fig. 1A). According to the sequence analysis results, ZmPGIP3 was not the most similar to ZmPGIP1 or $\mathrm{ZmPGIP} 2$, and the amino acid sequence homologies of ZmPGIP3 were $42.24 \%$ (ZmPGIP1) and $27.93 \%$ (ZmPGIP2). However, the amino acid sequence homologies were $61.71 \%$ (OsPGIP1) and $58.91 \%$ (OsPGIP2). The inhibition capability of PGIP toward the microbial PGs can be evaluated by activity assays, such as the agar diffusion assay. In our study, ZmPGIP3 inhibited a mixture of PGs from $R$. solani, thus demonstrating its PG-inhibiting capability. Therefore, ZmPGIP3 was closely related to plant disease resistance, and the expression of ZmPGIP3 was significantly induced by wounding, $R$. solani infection, JA, and SA. These results suggested that ZmPGIP3 might be involved in plant disease resistance.

$\mathrm{ZmPGIP3}$ was overexpressed in rice to investigate the role of ZmPGIP3 in plant disease resistance. According to the sequence analysis results, ZmPGIP3 was closely related to OsPGIP1 in rice (Fig. 1B). OsPGIP1 was found to enhance rice resistance to sheath blight and inhibit the degradation of cell wall tissue by PG (Chen et al. 2016; Wang et al. 2015b). ZmPGIP3 transgenic plants exhibited an enhanced resistance to sheath blight compared with that of WT plants in leaves or sheaths. The resistance of ZmPGIP3 transgenic lines was consistent with the expression levels of ZmPGIP3. Line OE2 was characterized by the highest ZmPGIP3 expression level, and it was the most resistant to rice sheath blight (Fig. 5D). OsPGIP1 and OsPGIP4 were resistant to single pathogens. OsPGIP1 and OsPGIP4 increase rice resistance to rice sheath blight and bacterial leaf streak, respectively (Feng et al. 2016; Wang et al. 2015b). In our study, ZmPGIP3 was also found to induce slight resistance to rice blast (data not shown). In previous reports, some abiotic stresses, such as salt and PEG, induce the expression of PGIP (Hu et al. 2012). In our study, the expression of ZmPGIP3 could be induced by $\mathrm{NaCl}$. However, no significant

TABLE 2. Agronomic traits of ZmPGIP3 transgenic plants grown in the paddy field conditions in $2018^{\mathrm{a}}$

\begin{tabular}{|c|c|c|c|c|c|c|c|c|}
\hline Lines & $\begin{array}{l}\text { No. of tillers } \\
\text { per plant }\end{array}$ & $\begin{array}{l}\text { Panicle no. } \\
\text { per plant }\end{array}$ & $\begin{array}{l}\text { Panicle length } \\
(\mathrm{cm})\end{array}$ & $\begin{array}{l}\text { No. of grains } \\
\text { per panicle }\end{array}$ & $\begin{array}{l}\text { Filled grains } \\
\text { per panicle }\end{array}$ & $\begin{array}{l}\text { Seed-setting } \\
\text { rate }(\%)\end{array}$ & $\begin{array}{l}\text { 1,000-Grain } \\
\text { weight }(\mathrm{g})\end{array}$ & $\begin{array}{c}\text { Grain yield } \\
\text { per plant }(\mathrm{g})\end{array}$ \\
\hline WT & $10.54 \pm 2.77$ & $10.54 \pm 2.77$ & $15.67 \pm 1.00$ & $114.39 \pm 12.24$ & $108.13 \pm 10.97$ & $94.6 \pm 1.93$ & $23.06 \pm 0.28$ & $21.06 \pm 0.73$ \\
\hline OE2 & $10.16 \pm 2.79$ & $10.16 \pm 2.79$ & $14.97 \pm 1.14$ & $112.03 \pm 15.15$ & $104.56 \pm 12.76$ & $93.89 \pm 2.25$ & $24.56 \pm 0.19^{b}$ & $20.77 \pm 0.89$ \\
\hline OE3 & $11.23 \pm 3.14$ & $11.19 \pm 3.07$ & $15.47 \pm 1.57$ & $109.35 \pm 14.79$ & $103.19 \pm 12.97$ & $94.53 \pm 2.86$ & $23.19 \pm 0.18^{\mathrm{c}}$ & $20.56 \pm 2.33$ \\
\hline
\end{tabular}

a OE2 and OE3 are two ZmPGIP3 transgenic plants. Values are mean \pm standard deviation $(n>15)$. WT, wild type.

b Significant difference at $P<0.01$.

c Significant difference at $P<0.05$. 
difference was observed between the transgenic lines and the WT rice under $\mathrm{NaCl}$ and PEG stress (data not shown).

Plants have developed several defense mechanisms, including the expression of a large number of defense genes, to combat the threat by pathogens (Gao et al. 2018; Liu et al. 2017). In this study, DGE analysis showed that the accumulation of some rice PGIP genes in transgenic rice enhanced the ability to inhibit $\mathrm{PGs}$ and reduce disease symptoms in transgenic plants attacked by sheath blight. Some studies have shown that OsPGIP1 can enhance the resistance to sheath blight by inhibiting PG activity and preventing pathogens from degrading the cell wall (Chen et al. 2016; Wang et al. 2015b). The expression of OsPGIP2 is induced immediately after $R$. solani infection in rice (Lu et al. 2012). OsPGIP2 overexpression enhances resistance to $S$. sclerotiorum in B. napus (Wang et al. 2018). OsPGIP4 can also positively regulate the defense response to pathogen in rice (Feng et al. 2016). In our study, 2 days postinoculation, the expression levels of the PGIP family genes $O s P G I P 1, O s P G I P 2$, and $O s P G I P 4$ significantly increased in the transgenic rice compared with those in the WT rice under normal growth conditions. These results showed that the expression of rice with PGIP family genes could be activated after inoculation with $R$. solani. However, the expression levels of OsPGIP1, OsPGIP2, and OsPGIP4 in the transgenic rice were significantly higher than those in the WT rice under normal growth conditions (Table 1). Studies have shown that the oligogalacturonides can be generated by the PG-PGIP interaction during the infection (Benedetti et al. 2015; Cervone et al. 1989). The overexpression of ZmPGIP3 may increase the level of endogenous oligogalacturonides in transgenic rice plants that, in turn, induce the expression of other PGIPs. These results suggested that ZmPGIP3 might activate the expression of rice PGIP genes to resist rice sheath blight.

Chitin is the main cell wall component of phytopathogenic fungi. Therefore, chitinase can degrade fungal cell wall components to resist diseases (Jashni et al. 2015). Some LRR family proteins are key players in plant disease resistance (Antolín-Llovera et al. 2014). In this study, the expression levels of chitinase activity genes and some LRR genes significantly increased in the transgenic rice compared with those in the WT rice, further indicating that ZmPGIP3 could improve sheath blight resistance.

JA and SA are the most important disease-resistant hormones in plants (Betsuyaku et al. 2018). The ZmPGIP3 expression was significantly induced by JA and SA (Fig. 3). Lipoxygenase (LOX) is a key enzyme in the JA synthesis pathway. OsLOX2 can activate LOX biosynthesis and participate in the JA pathway (Zhang et al. 2018). OsWRKY62 can be induced by SA to upregulate the expression of PR10 and regulate plant disease resistance (Liang et al. 2017). In this study, the expression levels of OsLOX2 and OsWRKY62 were upregulated in the transgenic rice compared with those in the WT rice. These results suggested that ZmPGIP3 could participate in JA and SA pathways to improve disease resistance.

The constitutive overexpression of stress-related genes often causes abnormal development and decreased productivity (Nakashima et al. 2007; Yu et al. 2013). Therefore, disease-resistant transgenic plants that can maintain high yields under normal conditions should be developed. In this study, ZmPGIP3 expression improved rice sheath blight resistance and did not affect the grain yield of transgenic rice. These results indicated that ZmPGIP3 is a promising candidate gene for the transgenic breeding of diseaseresistant and improved crops.

\section{LITERATURE CITED}

Agüero, C. B., Uratsu, S. L., Greve, C., Powell, A. L. T., Labavitch, J. M., Meredith, C. P., and Dandekar, A. M. 2005. Evaluation of tolerance to Pierce's disease and botrytis in transgenic plants of Vitis vinifera L. expressing the pear PGIP gene. Mol. Plant Pathol. 6:43-51.

Antolín-Llovera, M., Petutsching, E. K., Ried, M. K., Lipka, V., Nurnberger,

T., Robatzek, S., and Parniske, M. 2014. Knowing your friends and foes-plant receptor-like kinases as initiators of symbiosis or defence. New Phytol. 204:791-802.

Benedetti, M., Andreani, F., Leggio, C., Galantini, L., Di Matteo, A., Pavel, N. V., De Lorenzo, G., Cervone, F., Federici, L., and Sicilia, F. 2013. A single amino-acid substitution allows endo-polygalacturonase of Fusarium verticillioides to acquire recognition by PGIP2 from Phaseolus vulgaris. PLoS One 8:e80610.

Benedetti, M., Leggio, C., Federici, L., De Lorenzo, G., Pavel, N. V., and Cervone, F. 2011. Structural resolution of the complex between a fungal polygalacturonase and a plant polygalacturonase-inhibiting protein by small-angle X-ray scattering. Plant Physiol. 157:599-607.

Benedetti, M., Pontiggia, D., Raggi, S., Cheng, Z., Scaloni, F., Ferrari, S., Ausubel, F. M., Cervone, F., and De Lorenzo, G. 2015. Plant immunity triggered by engineered in vivo release of oligogalacturonides, damageassociated molecular patterns. Proc. Natl. Acad. Sci. USA 112: 5533-5538.

Betsuyaku, S., Katou, S., Takebayashi, Y., Sakakibara, H., Nomura, N., and Fukuda, H. 2018. Salicylic acid and jasmonic acid pathways are activated in spatially different domains around the infection site during effectortriggered immunity in Arabidopsis thaliana. Plant Cell Physiol. 59:439.

Borras-Hidalgo, O., Caprari, C., Hernandez-Estevez, I., De Lorenzo, G., and Cervone, F. 2012. A gene for plant protection: Expression of a bean polygalacturonase inhibitor in tobacco confers a strong resistance against Rhizoctonia solani and two oomycetes. Front. Plant Sci. 3:268.

Brandizzi, F., Snapp, E. L., Roberts, A. G., Lippincott-Schwartz, J., and Hawes, C. 2002. Membrane protein transport between the endoplasmic reticulum and the golgi in tobacco leaves is energy dependent but cytoskeleton independent: Evidence from selective photobleaching. Plant Cell 14:1293-1309.

Broetto, S. G., Fabi, J. P., and do Nascimento, J. R. O. 2015. Cloning and expression analysis of two putative papaya genes encoding polygalacturonaseinhibiting proteins. Postharvest Biol. Technol. 104:48-56.

Cervone, F., Hahn, M. G., Lorenzo, G. D., Darvill, A., and Albersheim, P. 1989. Host-pathogen interactions XXXIII. A plant protein converts a fungal pathogenesis factor into an elicitor of plant defense responses. Plant Physiol. 90:542-548.

Chen, X. J., Chen, Y., Zhang, L. N., Xu, B., Zhang, J. H., Chen, Z. X., Tong, Y. H., Zuo, S. M., and Xu, J. Y. 2016. Overexpression of OsPGIP1 enhances rice resistance to sheath blight. Plant Dis. 100:388-395.

De Lorenzo, G., D'Ovidio, R., and Cervone, F. 2001. The role of polygalacturonase-inhibiting proteins (PGIPS) in defense against pathogenic fungi. Annu. Rev. Phytopathol. 39:313-335.

De Lorenzo, G., and Ferrari, S. 2002. Polygalacturonase-inhibiting proteins in defense against phytopathogenic fungi. Curr. Opin. Plant Biol. 5:295-299.

Di Matteo, A., Bonivento, D., Tsernoglou, D., Federici, L., and Cervone, F. 2006. Polygalacturonase-inhibiting protein (PGIP) in plant defence: A structural view. Phytochemistry 67:528-533.

Di Matteo, A., Federici, L., Mattei, B., Salvi, G., Johnson, K. A., Savino, C., De Lorenzo, G., Tsernoglou, D., and Cervone, F. 2003. The crystal structure of polygalacturonase-inhibiting protein (PGIP), a leucine-rich repeat protein involved in plant defense. Proc. Natl. Acad. Sci. USA 100: 10124-10128

Federici, L., Di Matte, A., Fernandez-Recio, J., Tsernoglou, D., and Cervone, F. 2006. Polygalacturonase inhibiting proteins: Players in plant innate immunity? Trends Plant Sci. 11:65-70.

Feng, C. S., Zhang, X., Wu, T., Yuan, B., Ding, X. H., Yao, F. Y., and Chu, Z. H. 2016. The polygalacturonase-inhibiting protein 4 (OsPGIP4), a potential component of the qBlsr5a locus, confers resistance to bacterial leaf streak in rice. Planta 243:1297-1308.

Ferrari, S., Savatin, D. V., Sicilia, F., Gramegna, G., Cervone, F., and Lorenzo, G. D. 2013. Oligogalacturonides: Plant damage-associated molecular patterns and regulators of growth and development. Front. Plant Sci. 4:49.

Ferrari, S., Sella, L., Janni, M., De Lorenzo, G., Favaron, F., and D’Ovidio, R. 2012. Transgenic expression of polygalacturonase-inhibiting proteins in Arabidopsis and wheat increases resistance to the flower pathogen Fusarium graminearum. Plant Biol. 14:31-38.

Gao, Y., Jiang, W., Dai, Y., Xiao, N., Zhang, C. Q., Li, H., Lu, Y., Wu, M. Q., Tao, X. Y., Deng, D. X., and Chen, J. M. 2015. A maize phytochromeinteracting factor 3 improves drought and salt stress tolerance in rice. Plant Mol. Biol. 87:413-428.

Gao, Y., Lu, Y., Wu, M. Q., Liang, E. X., Li, Y., Zhang, D. P., Yin, Z. T., Ren, X. Y., Dai, Y., Deng, D. X., and Chen, J. M. 2016. Ability to remove $\mathrm{Na}^{+}$ and retain $\mathrm{K}^{+}$correlates with salt tolerance in two maize inbred lines seedlings. Front. Plant Sci. 7:1716.

Gao, Y., Wu, M. Q., Zhang, M. J., Jiang, W., Ren, X. Y., Liang, E. X., Zhang, D. P., Zhang, C. Q., Xiao, N., Li, Y., Dai, Y., and Chen, J. M. 2018. A maize phytochrome-interacting factors protein ZmPIF1 enhances drought tolerance by inducing stomatal closure and improves grain yield in Oryza sativa. Plant Biotechnol. J. 16:1375-1387. 
Hu, D. Q., Dai, R. Q., Wang, Y. H., Zhang, Y. H., Liu, Z. Y., Fang, R. J., Zhao, W. G., Li, L., Lin, Q., and Li, L. 2012. Molecular cloning, sequence analysis, and expression of the polygalacturonase-inhibiting protein (PGIP) gene in mulberry. Plant Mol. Biol. Report. 30:176-186.

Jang, S. H., Lee, B., Kim, C., Kim, S. J., Yim, J., Han, J. J., Lee, S., Kim, S. R., and An, G. 2003. The OsFOR1 gene encodes a polygalacturonase-inhibiting protein (PGIP) that regulates floral organ number in rice. Plant Mol. Biol. 53:357-372.

Janni, M., Di Giovanni, M., Roberti, S., Capodicasa, C., and D'Ovidio, R. 2006. Characterization of expressed Pgip genes in rice and wheat reveals similar extent of sequence variation to dicot PGIPs and identifies an active PGIP lacking an entire LRR repeat. Theor. Appl. Genet. 113:1233-1245.

Jashni, M. K., Mehrabi, R., Collemare, J., Mesarich, C. H., and de Wit, P. J. G. M. 2015. The battle in the apoplast: Further insights into the roles of proteases and their inhibitors in plant-pathogen interactions. Front. Plant Sci. 6:584.

Juge, N. 2006. Plant protein inhibitors of cell wall degrading enzymes. Trends Plant Sci. 11:359-367.

Kaewwongwal, A., Chen, J. B., Somta, P., Kongjaimun, A., Yimram, T., Chen, X., and Srinives, P. 2017. Novel alleles of two tightly linked genes encoding polygalacturonase-inhibiting proteins (VrPGIP1 and VrPGIP2) associated with the Br locus that confer bruchid (Callosobruchus spp.) resistance to mungbean (Vigna radiata) accession V2709. Front. Plant Sci. 8:1692.

Kalunke, R. M., Tundo, S., Benedetti, M., Cervone, F., De Lorenzo, G., and D'Ovidio, R. 2015. An update on polygalacturonase-inhibiting protein (PGIP), a leucine-rich repeat protein that protects crop plants against pathogens. Front. Plant Sci. 6:146.

Li, H. Y., and Smigocki, A. C. 2016. Wound induced Beta vulgaris polygalacturonase-inhibiting protein genes encode a longer leucine-rich repeat domain and inhibit fungal polygalacturonases. Physiol. Mol. Plant Pathol. 96:8-18.

Li, H. Y., and Smigocki, A. C. 2018. Sugar beet polygalacturonase-inhibiting proteins with 11 LRRs confer Rhizoctonia, Fusarium and Botrytis resistance in Nicotiana plants. Physiol. Mol. Plant Pathol. 102:200-208.

Liang, X. X., Chen, X. J., Li, C., Fan, J., and Guo, Z. J. 2017. Metabolic and transcriptional alternations for defense by interfering OsWRKY62 and OsWRKY76 transcriptions in rice. Sci. Rep. 7:2474.

Liu, N. N., Ma, X. W., Zhou, S. H., Wang, P., Sun, Y., Li, X. C., and Hou, Y. X. 2016. Molecular and functional characterization of a polygalacturonaseinhibiting protein from Cynanchum komarovii that confers fungal resistance in Arabidopsis. PLoS One 11:e0146959.

Liu, N. N., Sun, Y., Wang, P., Duan, H. X., Ge, X. Y., Li, X. C., Pei, Y. K., Li, F. G., and Hou, Y. X. 2018. Mutation of key amino acids in the polygalacturonase-inhibiting proteins CkPGIP1 and GhPGIP1 improves resistance to Verticillium wilt in cotton. Plant J. 96:546-561

Liu, N. N., Zhang, X. Y., Sun, Y., Wang, P., Li, X. C., Pei, Y. K., Li, F. G., and Hou, Y. X. 2017. Molecular evidence for the involvement of a polygalacturonase-inhibiting protein, GhPGIP1, in enhanced resistance to Verticillium and Fusarium wilts in cotton. Sci. Rep. 7:39840.

Liu, W. D., Liu, J. L., Triplett, L., Leach, J. E., and Wang, G. L. 2014. Novel insights into rice innate immunity against bacterial and fungal pathogens. Annu. Rev. Phytopathol. 52:213-241.
Livaja, M., Steinemann, S., and Scho, C. C. 2016. Sunflower polygalacturonase-inhibiting proteins (HaPGIP) are genetically conserved in cultivated sunflower (Helianthus anпииs L.) but diverse in wild species. Mol. Breed. 36:17.

Lu, L. X., Zhou, F., Zhou, Y., Fan, X. L., Ye, S. F., Wang, L., Chen, H., and Lin, Y. J. 2012. Expression profile analysis of the polygalacturonaseinhibiting protein genes in rice and their responses to phytohormones and fungal infection. Plant Cell Rep. 31:1173-1187.

Molla, K. A., Karmakar, S., Chanda, P. K., Ghosh, S., Sarkar, S. N., Datta, S. K., and Datta, K. 2013. Rice oxalate oxidase gene driven by green tissuespecific promoter increases tolerance to sheath blight pathogen (Rhizoctonia solani) in transgenic rice. Mol. Plant Pathol. 14:910-922.

Nakashima, K., Tran, L. S. P., Van Nguyen, D., Fujita, M., Maruyama, K., Todaka, D., Ito, Y., Hayashi, N., Shinozaki, K., and Yamaguchi-Shinozaki, K. 2007. Functional analysis of a NAC-type transcription factor OsNAC6 involved in abiotic and biotic stress-responsive gene expression in rice. Plant J. 51:617-630.

Richter, A., de Kathen, A., de Lorenzo, G., Briviba, K., Hain, R., Ramsay, G., Jacobsen, H. J., and Kiesecker, H. 2006. Transgenic peas (Pisum sativum) expressing polygalacturonase inhibiting protein from raspberry (Rubus idaeus) and stilbene synthase from grape (Vitis vinifera). Plant Cell Rep. 25: 1166-1173.

Tamura, K., Stecher, G., Peterson, D., Filipski, A., and Kumar, S. 2013. MEGA6: Molecular Evolutionary Genetics Analysis version 6.0. Mol. Biol. Evol. 30:2725-2729.

Wang, A. Y., Wei, X. N., Rong, W., Dang, L., Du, L. P., Qi, L., Xu, H. J., Shao, Y. J., and Zhang, Z. Y. 2015a. GmPGIP3 enhanced resistance to both takeall and common root rot diseases in transgenic wheat. Funct. Integr. Genomics 15:375-381.

Wang, R., Lu, L. X., Pan, X. B., Hu, Z. L., Ling, F., Yan, Y., Liu, Y. M., and Lin, Y. J. 2015b. Functional analysis of OsPGIP1 in rice sheath blight resistance. Plant Mol. Biol. 87:181-191.

Wang, X. J., Zhu, X. P., Tooley, P., and Zhang, X. G. 2013. Cloning and functional analysis of three genes encoding polygalacturonase-inhibiting proteins from Capsicum annиum and transgenic CaPGIP1 in tobacco in relation to increased resistance to two fungal pathogens. Plant Mol. Biol. 81:379-400.

Wang, Z. R., Wan, L. L., Xin, Q., Chen, Y., Zhang, X. H., Dong, F. M., Hong, D. F., and Yang, G. S. 2018. Overexpression of OsPGIP2 confers Sclerotinia sclerotiorum resistance in Brassica napus through increased activation of defense mechanisms. J. Exp. Bot. 69:3141-3155.

Yu, L. H., Chen, X., Wang, Z., Wang, S. M., Wang, Y. P., Zhu, Q. S., Li, S. G., and Xiang, C. B. 2013. Arabidopsis enhanced drought tolerance1/ HOMEODOMAIN GLABROUS11 confers drought tolerance in transgenic rice without yield penalty. Plant Physiol. 162:1378-1391.

Zhang, X., Bao, Y. L., Shan, D. Q., Wang, Z. H., Song, X. N., Wang, Z. Y., Wang, J. S., He, L. Q., Wu, L., Zhang, Z. G., Niu, D. D., Jin, H. L., and Zhao, H. W. 2018. Magnaporthe oryzae induces the expression of a microRNA to suppress the immune response in rice. Plant Physiol. 177:352-368. 